\title{
Intelligent fire detection and alert system using labVIEW
}

\author{
Fakrulradzi Idris ${ }^{1}$, Norlezah Hashim², Ahmad FauzanKadmin ${ }^{3}$, Lee Boon Yee \\ ${ }^{1,4}$ Centre for Telecommunication Research \& Innovation (CeTRI), \\ Fakulti Kejuruteraan Elektronik dan Kejuruteraan Komputer (FKEKK), Universiti Teknikal Malaysia Melaka (UTeM), \\ Malaysia \\ ${ }^{2,3}$ Centre for Telecommunication Research \& Innovation (CeTRI), Fakulti Teknologi Kejuruteraan (FTK), \\ Universiti Teknikal Malaysia Melaka (UTeM), Malaysia
}

\begin{tabular}{|c|c|}
\hline Article Info & ABSTRACT \\
\hline Article history: & \multirow{10}{*}{$\begin{array}{l}\text { Fire detection systems are designed to discover fires and allow the safe } \\
\text { evacuation of occupants as well as protecting the safety of emergency } \\
\text { response personnel. This paper describes the design and development of a } \\
\text { fire detection and alert system. Temperature and flame sensors are used to } \\
\text { indicate the occurrence of fire. This work consists of two parts, which are } \\
\text { transmitter and receiver, both using ZigBee wireless technology. Arduino } \\
\text { Uno is used as the microcontroller at the transmitter part to control the sensor } \\
\text { nodes and give alert when over temperature and flame are detected. At the } \\
\text { transmitter, the collected data from the sensors are transmitted by an XBee } \\
\text { module operated as router node. At the receiver side, an XBee coordinator } \\
\text { module which is attached to a computer using USB to serial communication } \\
\text { captured the data for further processing. In addition, an interactive and user- } \\
\text { friendly Graphical User Interface (GUI) is developed. LabVIEW software is } \\
\text { used to design the GUI which displays and analyze the possibility of fire } \\
\text { happening. The system can display the fire location and provides early } \\
\text { warning to allow occupants to escape the building safely. }\end{array}$} \\
\hline Received Aug 21, 2018 & \\
\hline Revised Nov 26, 2018 & \\
\hline Accepted Dec 25, 2018 & \\
\hline Keywords: & \\
\hline Alert & \\
\hline Arduino & \\
\hline Fire detection & \\
\hline LabVIEW & \\
\hline ZigBee & \\
\hline
\end{tabular}

Copyright $(2019$ Institute of Advanced Engineering and Science. All rights reserved.

\section{Corresponding Author:}

Fakrulradzi Idris,

Centre for Telecommunication Research \& Innovation (CeTRI),

Fakulti Kejuruteraan Elektronik dan Kejuruteraan Komputer (FKEKK),

Universiti Teknikal Malaysia Melaka (UTeM),

Hang Tuah Jaya, 76100 Durian Tunggal, Melaka, Malaysia.

Email: fakrulradzi@utem.edu.my

\section{INTRODUCTION}

Fire detection and alert systems are very important for early fire detection and speeding the process of fire control. Conventional fire alarm systems [1] have been usedfor quite a long time. They are mostly used in large buildings and smaller sites such as stores, restaurants, schools, and apartments. A conventional system utilizes initiating circuits which are connected to sensors and wired in parallel. These sensors are designed to decrease the circuits resistance when the environmental influence on any sensor exceeds a predetermined threshold.Usually, a floor plan of the building is placed near the main entrance with a diagram of the defined zones and LEDs indicating whether a particular circuit or zone has been activated. One advantage of this system is that it is a cost effective for small applications. The main issue with a conventional fire alarm system is that we cannot tell which specific device or location has been activated within a circuit. For example, fire might occur in one small room but the fire could exist anywhere within a zone.This could delay emergency responders from locating the fire.

Wireless fire alarm [2] can be used to reduce the cost of conventional wired fire alarm system. Advances in technology have made wireless based system as reliable as the wired one. Fire alarm system that utilizes wireless communications such as Wi-Fi [3]-[5] have several advantages. The main advantage of a 
wireless system is its portability. This means that it can be installed anywhereand easy to modify when there is need to update the layout of the building. Wireless fire alarms can also be moved around as required to obtain the best protection possible. However, wireless fire alarms have range restrictions. For large building or areas, a wireless system can have an issue with transmitting information to the main control panel.

There are many works that investigated fire detection system utilizing different technologies and components [6]-[10]. In [6], ZigBee is used as the wireless technology in a fire detection system. The work in [7] developeda low power and multi-parameter composite fire detection node to detect temperature, smoke concentration and $\mathrm{CO}$ gas concentration. The hardware and software implementation are based on $2.4 \mathrm{GHz}$ wireless communication chip, CC2430. ZigBee is adopted in the system to form reliable wireless communication. This system uses fusion theory to handle the data to determine the possibility of fire happening.

A wireless fire detection node based on wireless sensor network (WSN) which can detect temperature, humidity and smoke concentration is proposed in [8]. Shortest path routing algorithm is proposed according to multi-hop transmission based on CSMA/CA principle. The sensor nodes can connect each other automatically and the sensor data can be transmitted within minimum hops to build a real-time fire monitoring system.

The work in [9] proposed WSN technology to the fire safety which can actualize wireless requirement, network, and intelligent fire monitoring. This system acquired data of temperature and smoke concentration. Fire detection nodes using SOC CC2430 as the control unit to realize the communication between nodes. The software running on the nodes applies CSMA/CA Medium Access Control (MAC) protocol and a shortest path routing algorithm for data-transmission in multi-hop. Agateway is designed and implemented based on ARM9 and Linux, which connects wireless fire detection network and the Internet. It has a strong processing, storage and network communication capabilities, Remote users may share real-time fire parameter from Internet which connects with the wireless fire data acquisition network through the gateway.

A fire monitoring system is designed in [10]. The hardware part includes the fire detection trigger module, the control module and the monitoring center module. The fire detection trigger module transmits the smoke and temperature parameters to the control module through CC2430. The control module analyzes the information coming from the detector and transmits the fire information to the monitoring center. The monitoring center module is responsible for monitoring the whole operation condition of the system and making decision. The software design of the system is mainly used to initialize the device and revive or send the parameters or command.

In this work, an intelligent fire detection and alert system based on ZigBee technology [11], [12] which are using temperature and flame sensors are designed. ZigBee is a typical wireless communication technology which is widely used in wireless sensing network. The reason of using two types of sensor is to reduce the possibility of false alarms. In addition, an interactive and user friendly Graphical User Interface (GUI) is designed to provide the temperature values, and alert the occupants when fire is discovered.

The rest of the paper is organized as follows. Section 2 provides the research method. Result and discussions is explained in Section 3. Finally, Section 4 concludes this paper.

\section{RESEARCH METHOD}

The proposed system consists of two parts which are transmitter and receiver parts. The transmitter will be controlled by an Arduino board while the receiver part will be controlled by LabVIEW GUI. Figure 1 shows the block diagram of the system. To ensure the expandability of the system, two transmitters nodes and a single receiver node are designed.

\subsection{Transmitter}

Each transmitter has the same hardware configurations. It consists of an Arduino UNO board, LM35 temperature sensor, flame sensor, a liquid crystal display, Light Emitting Diodes (LEDs) and a buzzer. The LM35 series are precision integrated-circuit temperature sensors, whose output voltage is linearly proportional to the Celsius temperature. Thus, LM35 has an advantage over linear temperature sensors calibrated in Kelvin. The flame sensor module comes with flame sensor, adjustable digital filter for digital output and it also reserve the original analog output. The flame sensor can be used to detect fire or other light source with wavelength of $760 \mathrm{~nm} \sim 1100 \mathrm{~nm}$ light. 


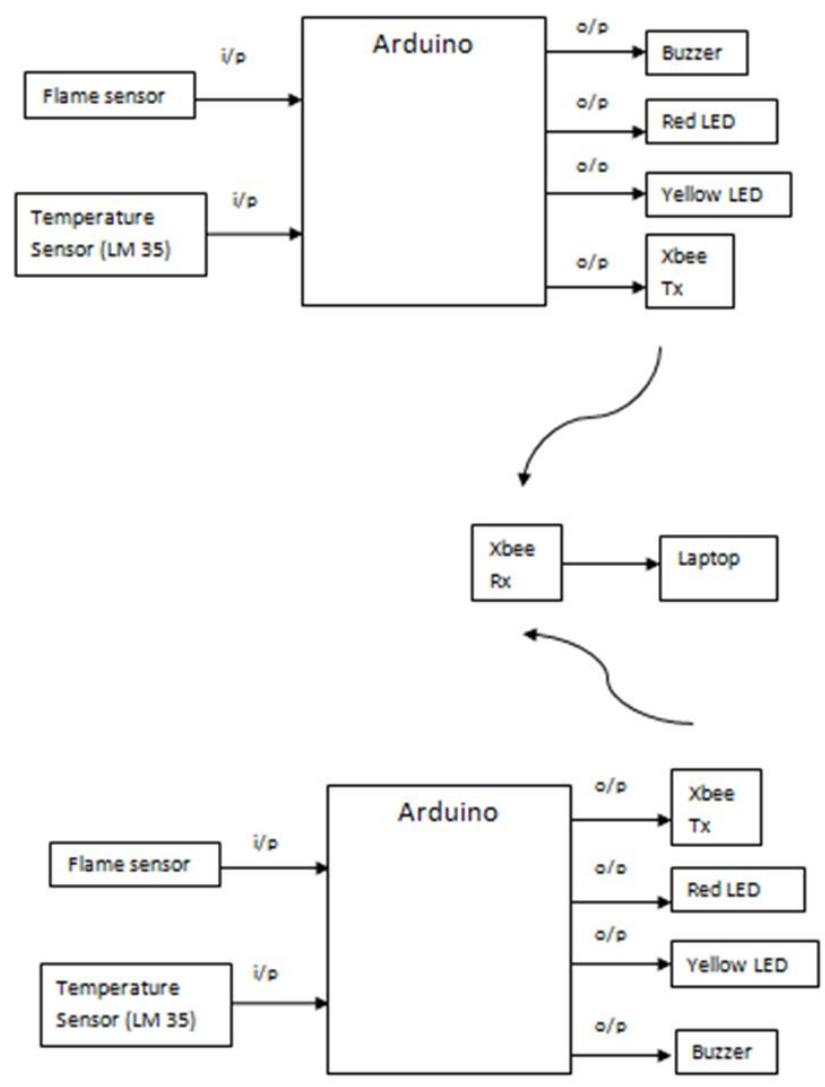

Figure 1. Block diagram of overall system

An 16x2 LCD display is very basic module and is very commonly used in various devices and circuits. This LCD is economical, easily programmable and no limitation of displaying special and custom characters. It can display 16 characters per line and there are 2 such lines. Three LEDs are used to provide the status of the system to end users. One LED is used to display a warning if the temperature exceeds a predefined threshold value while another one provides status for the flame sensor. The third LED is the most important one as it shows that fire is detected by the system which causes the buzzer to be turned on. A detailed wiring of the components in the transmitter is provided in Figure 2.

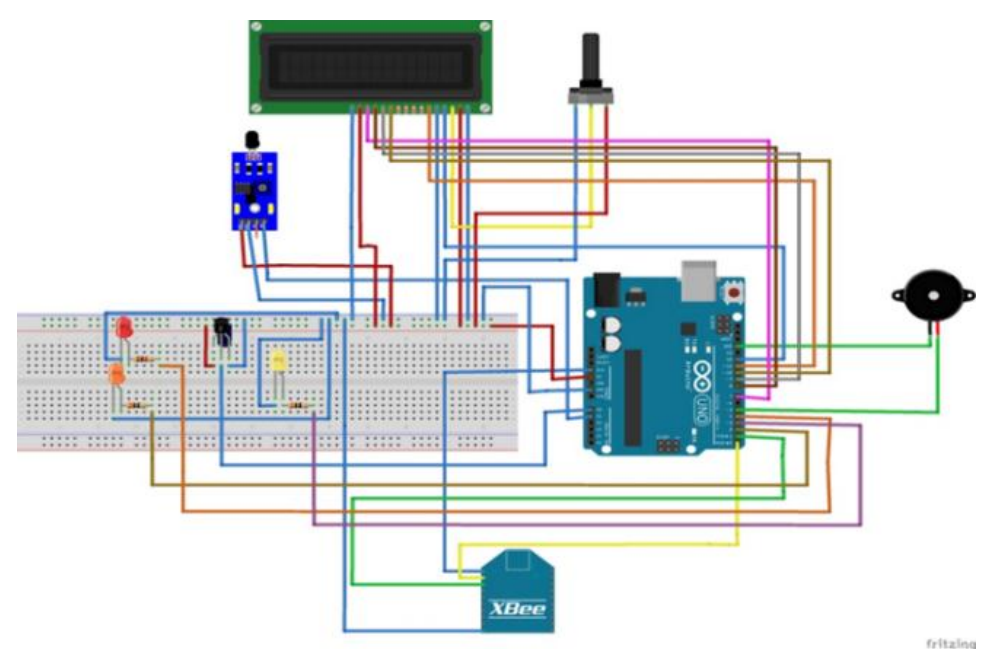

Figure 2. Connection diagram for the transmitter 
The first and the second transmitter are designated as XBee1 and XBee 2 respectively. When the transmitters are turned on, the serial monitor application will display the value of the temperature sensor and the voltage of the flame sensor. In order for receiver to differentiate between two different transmitters, offsets are assigned in the program as shown in Figure 3. Offset of " 01 " for temperature sensor and " 03 " for flame sensor are used in XBee1 while offset of "02" for temperature sensor and "04" for flame sensor are used in XBee2.

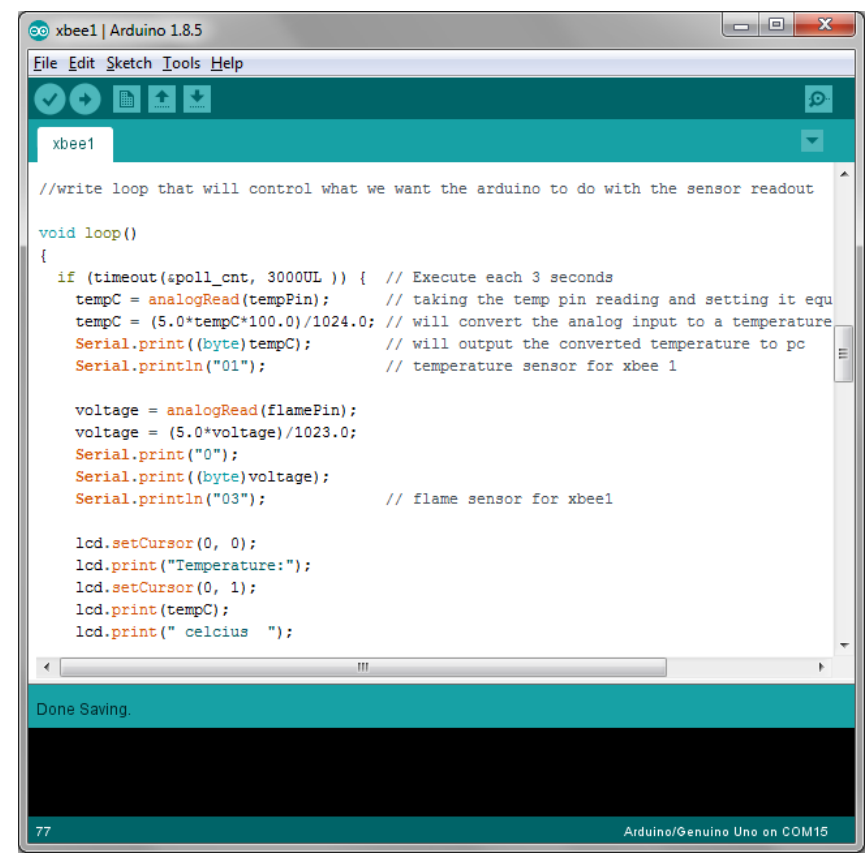

Figure 3. Offset used to differentiate the XBee transmitters

\subsection{Receiver}

The receiver consists of a Digi Xbee module series 2 attached to Explorer USB board [12]. The board is used to provide the USB-to-serial interface between the Xbee module and the computer. The Xbee module is configured to operate act as a coordinator and receives data from the transmitters which have been set as routers.

\section{RESULTS AND DISCUSSION} its operation.

This section provides the prototype of the intelligent fire detection and alert system and

\subsection{Transmitter}

The prototype of one of the transmitters for the fire detection and alert system is shown in Figure 4. Figure 5 shows the system status at the transmitter side whenfire is detectedand the temperature exceeds a predefined warning threshold. The yellow warning LED will turn on and the LCD displays the status. If the temperature exceeds the value set as over temperature, the red LED and buzzer will be turned on as presented in Figure6. Similarly, the LCD displays the current status of the system and alert occupants so that they can escape the building safely. 


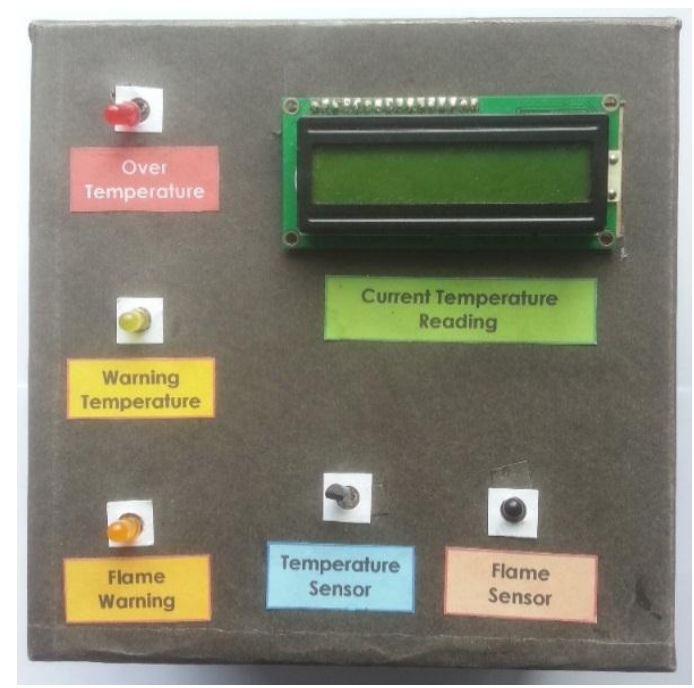

Figure 4. Product prototype
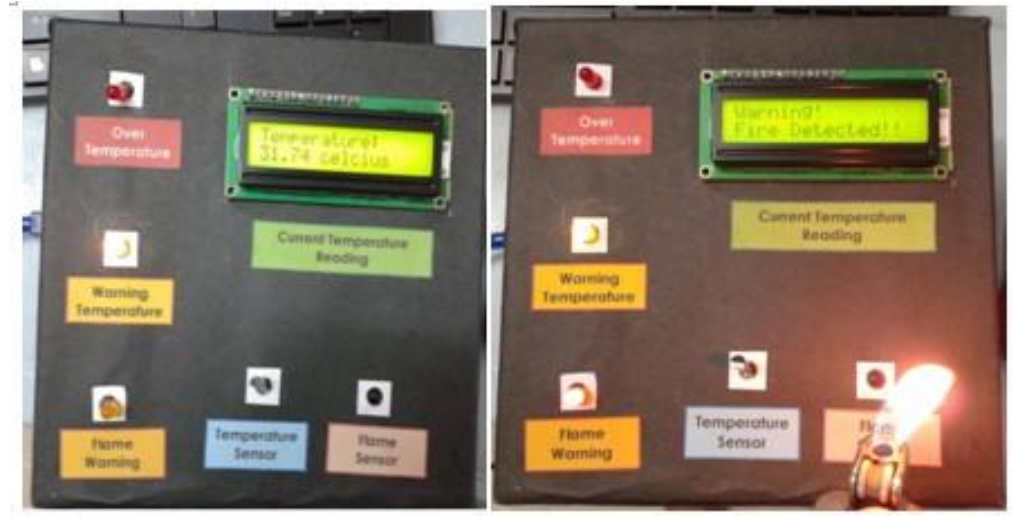

Figure 5. Temperature warning and fire detection
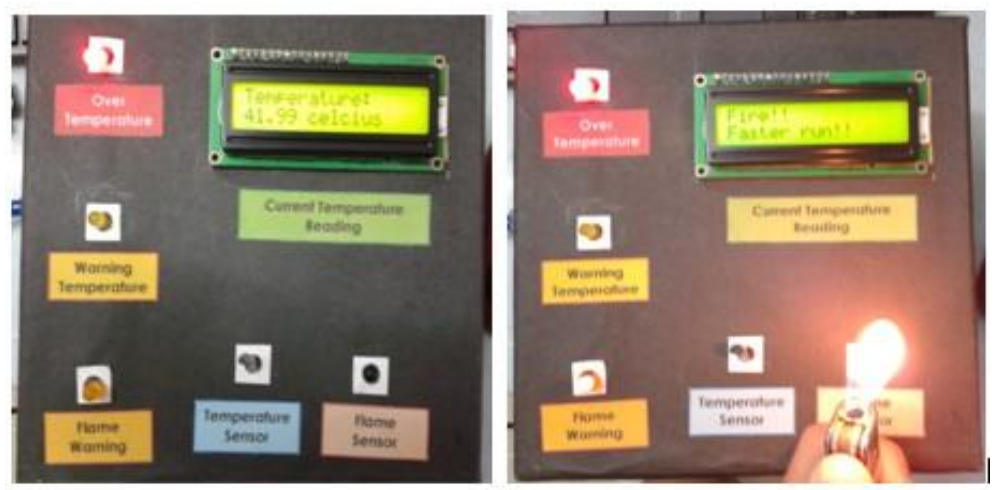

Figure 6. Over temperature and fire alert notification

\subsection{Receiver}

An XBee coordinator is connected to a computer to receive data from the transmitter and displayed them using LabVIEW GUI. Using the built-in serial monitor application in Arduino, the data forwarded by the transmitter e.g. XBee2 can be viewed as shown in Figure7. Figure 8 shows the front panel of the system's GUI that has been designed using LabVIEW 2012 software. There are few sections in this system which is 
Current Reading, On and Reset switch, Temperature Range, Analysis Data, Alert System, and History Graph. User can choose to view the status of transmitter 1 or transmitter 2 by selecting XBee 1 or XBee 2 respectively on the tab control on top of the front panel.

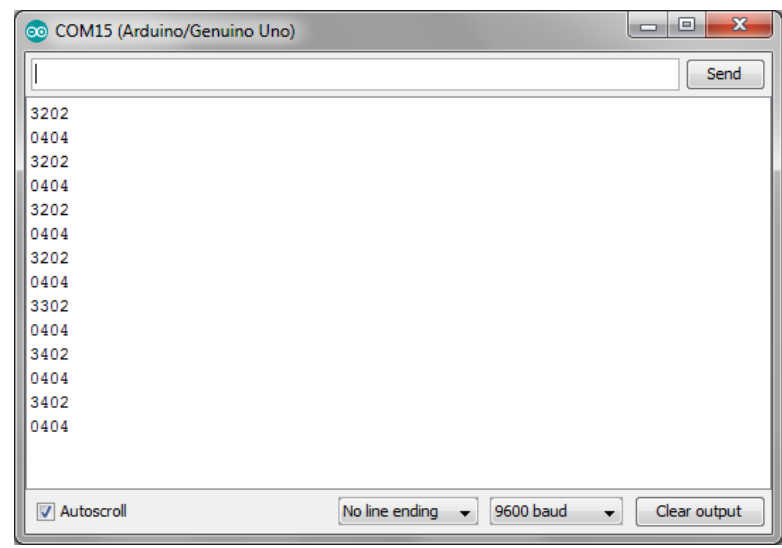

Figure 7. Serial monitor

When the switch is turned on, the system starts to display the current reading of the temperature and calculates the mean, minimum and maximum values received from the serial port. Figure 9 shows the warning alert when the current temperature value surpasses the low limit of the temperature range that has been set.

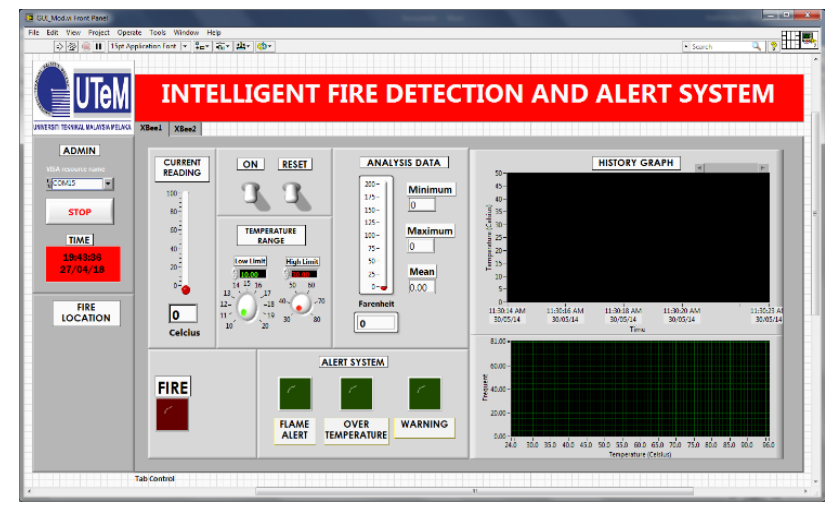

Figure 8. LabVIEW GUI

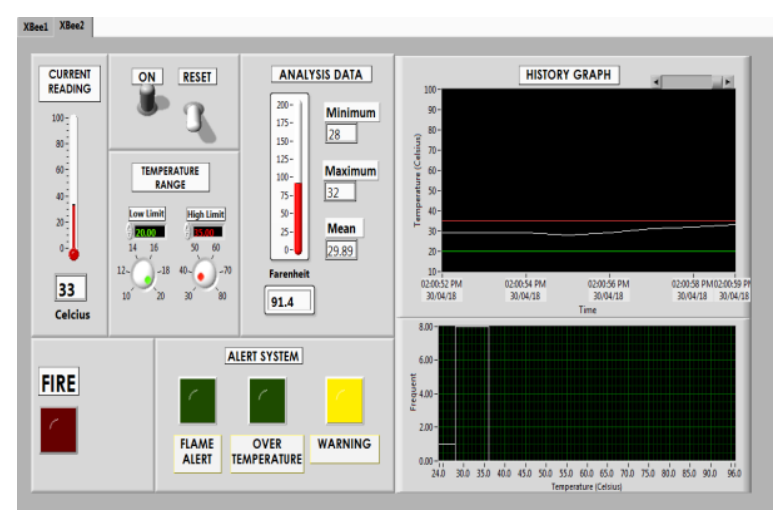

Figure 9. Temperature warning

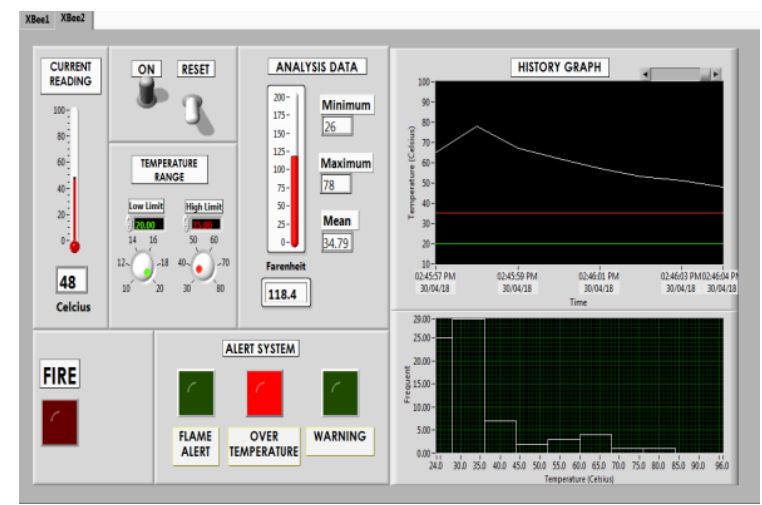

Figure 10. Over temperature 
Figure 10 shows the over temperature alert when the current temperature exceeds the high limit of the range. Figure 11 presents the system status when over temperature and flame is detected. The location on fire will be notified so that the emergency response professionals can take charge of controlling the fire as quickly as possible.

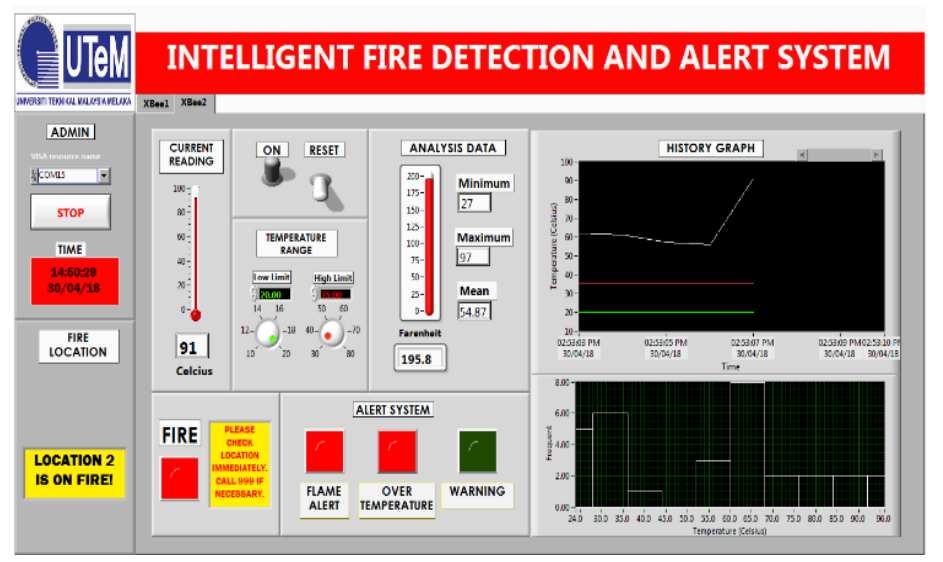

Figure 11. Over temperature and flame detected

\section{CONCLUSION}

In this paper, we have designed an intelligent fire detection and alert system which using multiple sensors to discover fires in their early stage. ZigBee technology is used to provide the wireless connection between the transmitters and the receiver. In addition, using a LabVIEW based GUI, the system can provide alert when the temperature value surpasses the warning and over temperature ranges. One advantage of this system is that the alerts are provided at both the transmitter and receiver sides which allow occupants to escape the building safely. Furthermore, the exact location on fire is provided by the system so that emergency response team can locate and control the fire as quickly as possible.

\section{ACKNOWLEDGEMENTS}

We would like to thank Universiti Teknikal Malaysia Melaka (UTeM) and Ministry of Higher Education for sponsoring this research under RAGS/1/2015/ICT01/UTEM/03/B00121.

\section{REFERENCES}

[1] "Conventional fire alarm system", [Online]. Available: http://www.orrprotection.com/firealarm/conventional/

[2] "Pro and Cons of Wireless Fire Alarms", [Online]. Available: http://www.guardianfireprotection.com/blog/prosand-cons-wireless-fire-alarms

[3] N. Hashim, N. F. A. M. Azmi, F. Idris and N. Rahim, "Smartphone Activated Door Lock Using WiFi," ARPN Journal of Engineering and Applied Sciences, vol. 11, no. 5, pp. 3309-3312, Mar 2016.

[4] F. Idris , N. Hashim, "Deployment and Evaluation of a Multi-Hop Wireless Network," International Journal of Computer Trends and Technology (IJCTT), vol. 5, no. 2, pp. 80-83, Nov 2013.

[5] F. Rahmat, F. Idris, M. Azri, V. Kanathasan, N. Sarimin and M. H. Mohamad, "Performance Analysis of VoIP in Multi-hop Wireless Network," 2012 IEEE Asia-Pacific Conference on Applied Electromagnetics (APACE), Melaka, pp. 51-55, 2012.

[6] Y. Hongyan, G. Shuqin, H. Ligang, W. Jinhui, P. Xiaohong and W. Wuchen, "Research of Fire Detecting System Based on ZigBee Wireless Network," International Conference on Industrial Control and Electronics Engineering, Xi'an, pp. 251-253, 2012.

[7] S. Liu, D. Tu and Y. Zhang, "Multiparameter Fire Detection Based on Wireless Sensor Network," 2009 IEEE International Conference on Intelligent Computing and Intelligent Systems, Shanghai, pp. 203-206, 2009.

[8] S. Liu, W. Xie and Y. Zhang, "Research and Implementation of WSN in Fire Safety Applications," 2010 6th International Conference on Wireless Communications Networking and Mobile Computing (WiCOM), Chengdu, pp. 1-4, 2010.

[9] C. Zhang and J. Li, "Fire Monitoring System Design Based on ZigBee Wireless Network Technology," World Automation Congress 2012, Puerto Vallarta, Mexico, pp. 1-4, 2012. 
[10] Y. S. Lim et al., "A Fire Detection and Rescue Support Framework with Wireless Sensor Networks," International Conference on Convergence Information Technology (ICCIT 2007), Gyeongju, 2007, pp. 135-138, 2007.

[11] N. Hashim, M. A. H. A. Razak, F. Idris, "Home Security System Using Zigbee,” Jurnal Teknologi, vol. 74, no. 10, pp. 29-34, Mar 2015.

[12] R. Faludi. O’Reilly, “Building Wireless Sensor Network,”lst edition. O’Reilly, 2011.

\section{BIOGRAPHIES OF AUTHORS}

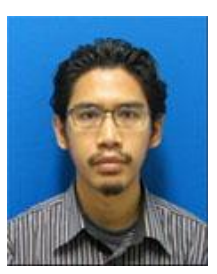

Fakrulradzi Idris received the B.Eng. and the M.Eng. degrees from Universiti Teknologi Malaysia in 2007 and 2008 respectively. He is currently pursuing the Ph.D. degree with the School of Electrical and Electronic Engineering, The University of Manchester, U.K. His research interests include Device-to-Device communications, non-orthogonal multiple access and 5G networks.

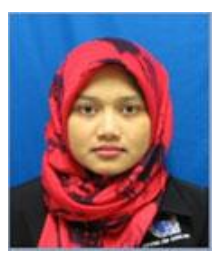

Norlezah Hashim obtained her first degree in 2006 from University of Malaya and her master degree from Universiti Teknologi Malaysia in 2014. In the past, she worked in Qimonda and Panasonic as a project and R\&D engineer. Currently she is serving UTeM as a lecturer in Faculty of Engineering Technology. Her current publications and research interest are based on wireless communication and LoRa.

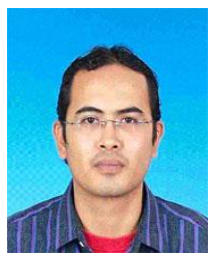

Currently attached with UTeM as a researcher, Ahmad Fauzan B. Kadmin CEng. P.Tech. has over 14 years of experience in electronic \& computer engineering field with technical expert in R\&D engineering, computer vision \& medical electronics. He Graduated with a Bachelor Degree in Electronics Engineering from Universiti Sains Malaysia and Master Degree in Computer \& Communication Engineering from Universiti Kebangsaan Malaysia. Previously, he worked with Megasteel Sdn. Bhd., Samsung SDI(M) Sdn. Bhd. and Agensi Angkasa Negara. He published several technical and engineering paperworks in image processing and medical electronics. 